\section{International Scientific Journal Theoretical \& Applied Science}

\section{Saida Ragim Mamedova Senior Lecturer of the Department «Organization of business and management» of the Sumgayit State University, Sumgayit, Azerbaijan Republic nauka-xxi@mail.ru}

Year: $2017 \quad$ Issue: $07 \quad$ Volume: 51

Published: $30.07 .2017 \quad$ http://T-Science.org

SECTION 31. Economic research, finance, innovation, risk management.

\title{
THE PROBLEMS AND MODELING OF DEVELOPMENT OF INNOVATIVE ACTIVITY IN THE CHEMICAL COMPANIES OF AZERBAIJAN
}

Abstract: The problems and modeling of development of innovative activity in the chemical companies of Azerbaijan are investigated in article. The development processes of the chemical industry and their innovative features are analyzed. The main content of the innovation requirement and the state of the fixed assets of chemical enterprises are disclosed.The importance of modeling the development of innovation activity using high technologies and productive innovative functions is considered. The necessity of accelerating the innovation of chemical enterprises with the aim of increasing their competitiveness under the current conditions is substantiated.

A number of proposals and recommendations on modelling development and solve the problems concerning the intensification of innovation in chemical enterprises of Azerbaijan are given at the end of the article.

Key words: Azerbaijan, innovative activity, chemical industry, chemical companies, innovative function.

Language: Russian

Citation: Mamedova SR (2017) THE PROBLEMS AND MODELING OF DEVELOPMENT OF INNOVATIVE ACTIVITY IN THE CHEMICAL COMPANIES OF AZERBAIJAN. ISJ Theoretical \& Applied Science, 07 (51): 79-86.

Soi: http://s-o-i.org/1.1/TAS-07-51-14 Doi: crossef https://dx.doi.org/10.15863/TAS.2017.07.51.14

\section{ПРОБЛЕМЫ И МОДЕЛИРОВАНИЕ РАЗВИТИЯ ИННОВАЦИОННОЙ ДЕЯТЕЛЬНОСТИ В ХИМИЧЕСКИХ ПРЕДПРИЯТИЯХ АЗЕРБАЙДЖАНА}

Аннотация: В статье исследованы проблемы и моделирование развития инновационной деятельности в химических предприятиях Азербайджана. Анализированы процессы развития химической промышленности и их инновационная оснащённость. Раскрыто основное содержание инновационной потребности и состояние основных фондов химических предприятий. Рассмотрена важность моделирования развития инновационной деятельности с применением высоких технологий и продуктивных инновационных функций. Обоснована необходимость ускорения инноватизации химических предприятий с целью повышения их конкурентоспособности в нынешних условиях.

В конце статьи дан ряд рекомендаций и предложений по моделированию развития и разрешения проблем в интенсификации инновационной деятельности в химических предприятиях Азербайджана.

Ключевые слова: Азербайджан, инновачионная деятельность, химическая промышленность, химические предприятия, инновационная функция.

\section{Introduction}

В последние десятилетия в Азербайджане происходит интенсификация проводимых крупномасштабных работ по модернизации и обновлению основных фондов и оборудования промышленных секторов страны. Производятся структурные изменения и институциональное совершенствование по управлению ведущих секторов промышленности Азербайджана. Отметим, что одним из важных и мощных секторов промышленности страны является химический сектор, который имеет крупный потенциал для саморазвития, расширения производства конкурентоспособных и экспорноориентированных продукций.

\section{Materials and Methods}

Химическая промышленность Азербайджана является одной из традиционных отраслей, которая развита наряду с нефтяной 
промышленностью. Ещё в период нахождения в составе СССР, химическая промышленность страны входила в число одной из крупнейших отраслей союзного государства и в нём функционировали свыше 30-ти химических предприятий, в которых производились сотни наименований продукций. Развитие химической промышленности Азербайджана началась значительно позже, чем нефтеперерабатывающая. Несмотря на это, во второй половине ХХ века, в стране развитие химической промышленности обгоняло практически все другие отрасли Азербайджанской Республики. В 1970-1985 годы химическая промышленность в Азербайджане по основным видам продукции была достигнута роста, превышающего в 2 раза и больше, более того, $20 \%$-ов всего промышленного потенциала республики было сосредоточено в химическом комплексе. Именно в этот период был заложен фундамент строительства крупных химических и нефтехимических установок «ЭП-300» и «Полимир-120», в Сумгайытском химическом центре и его основных предприятиях: ПО «Синтезкаучук» и ПО «Оргсинтез», которые были введены в эксплуатацию в конце 1988 года. Однако с распадом СССР, в начале 1990-х годов, в Азербайджане произошли кардинальные изменения в деятельности крупных химических предприятий. Предприятия, которые раньше были союзного назначения, потеряли основные хозяйственные кооперационные связи, партнёров по поставке основных сырьевых ресурсов и потребителей готовых продукций. Ведь раньше деятельностью этих предприятий управляли централизовано, то есть вопросы объёма производства и конкретной отправки готовой продукции распределялись по разнарядкам из центральных соответствующих министерств, в результате чего предприятиям оставалось лишь исправно производить продукцию и отправлять их по конкретным указанным адресам. Но в условиях преобразования централизованной административно-командной системы и рыночного хозяйствования в корне изменилась деятельность крупных химических предприятий уже суверенного Азербайджана. В первые годы восстановления суверенитета - в начале 1990-х годов до 2001-го года многие крупных химические предприятия Азербайджана потеряли свои основные мощности производства, либо установки вышли из строя и не восстанавливались, либо из-за низкой обеспеченности сырьевыми ресурсами эти установки полностью остановились, а потом их не восстановили или не было смысла их восстанавливать. Более того, в 90-х годах объём добычи нефти в Азербайджане не был в состоянии загрузить мощность нефтеперерабатывающих установок в Республике, и в результате имеющийся в наличии объём сырья для химического комплекса составил лишь 20-25 \% от его перерабатывающей мощности. Отрадно, что с реализации в стране новой нефтяной стратегии удалось восстановить и существенно увеличить добычу нефти и газа[1, c.37]. К большому сожалению, несмотря на увеличение добычи нефти и газа, модернизация химической промышленности и химических предприятий Азербайджана затянулась. В результате чего, рациональное использование имеющихся мощностей химического комплекса существенно отстаёт от общего темпа экономического развития и от процессов инноватизации разных секторов экономики страны[2]. Отметим, что с распоряжением Президента Азербайджанской Республики от 2-го апреля 2010 года «О совершенствовании механизмов управления в нефтехимической промышленности» все основные государственные химические и нефтехимические предприятия были введены в состав SOCAR и был образован ПО «Азерихимия»[3]. После этого намного оживились модернизационные работы основных крупных установок в заводе «ЭтиленПолиэтилен», однако ряды крупных предприятий с изношенным оборудованием вовсе были ликвидированы (завод «Синтезкаучук», «Оргсинтез», «Поверхстно-активных веществ» и прочее). Несмотря на это удалось, за счёт частичной модернизации крупных установок «ЭП-300», увеличить переработку основного вида химического сырья - нафта (химических бензин). В Таблице 1 даны основные показатели по обеспечению сырьем и производство продукции ПО «Азерихимия» SOCAR за 20102015 годы[4].

Таблица 1

Основные показатели по обеспечению сырьем и производство продукции ПО «Азерихимия» SOCAR (2010-2015)

\begin{tabular}{|l|l|l|l|l|l|l|l|}
\hline Наименование продукции & \multirow{2}{*}{\begin{tabular}{c} 
Единица \\
\cline { 5 - 8 }
\end{tabular}} & \multicolumn{5}{|c|}{ Гзды } \\
\cline { 6 - 9 } & изерения & 2010 & 2011 & 2012 & 2013 & 2014 & 2015 \\
\hline Сырье & тыс. тон & 224,3 & 284,5 & 256,6 & 287,2 & 373,4 & 374,8 \\
\hline Полиэтилен & тыс. тон & 53,5 & 74,5 & 67,1 & 76,2 & 101,0 & 103,5 \\
\hline Этилен & тыс. тон & 55,0 & 77,5 & 69,2 & 78,5 & 104,0 & 106,7 \\
\hline Пропилен & тыс. тон & 28,6 & 40,2 & 35,0 & 40,9 & 56,5 & 56,4 \\
\hline
\end{tabular}




\begin{tabular}{|c|c|c|c|c|c|c|}
\hline Impact Factor: & $\begin{array}{l}\text { ISRA (India) } \\
\text { ISI (Dubai, UAF } \\
\text { GIF (Australia) } \\
\text { JIF }\end{array}$ & $\begin{array}{l}=1.344 \\
=0.829 \\
=0.564 \\
=1.500\end{array}$ & $\begin{array}{l}\text { SIS (USA) } \\
\text { PИНЦ (Russia) } \\
\text { ESJI (KZ) } \\
\text { SJIF (Morocco) }\end{array}$ & $\begin{array}{l}=0.912 \\
=0.234 \\
=3.860 \\
=\mathbf{2 . 0 3 1}\end{array}$ & $\begin{array}{l}\text { ICV (Poland) } \\
\text { PIF (India) } \\
\text { IBI (India) }\end{array}$ & $\begin{array}{l}=6.630 \\
=1.940 \\
=4.260\end{array}$ \\
\hline
\end{tabular}

\begin{tabular}{|l|l|l|l|l|l|l|l|}
\hline $\begin{array}{l}\text { Бутилен-Бутадиеновая } \\
\text { фракция }\end{array}$ & тыс. тон & 25,0 & 27,3 & 20,3 & 24,8 & 30,1 & 24,8 \\
\hline Жидкая пиролизная смола & тыс. тон & 54,0 & 58,2 & 54,2 & 55,4 & 71,8 & 73,4 \\
\hline $\begin{array}{l}\text { Тяжелая пиролизная } \\
\text { смола }\end{array}$ & тыс. тон & 10,6 & 11,7 & 13,1 & 15,3 & 18,7 & 22,1 \\
\hline $\begin{array}{l}\text { Абсалютированный } \\
\text { изопропиловый спирт }\end{array}$ & тыс. тон & 10,0 & 10,9 & 7,4 & 13,8 & 10,6 & 12,3 \\
\hline $\begin{array}{l}\text { Товарная продукция: } \\
\text { всего }\end{array}$ & $\begin{array}{l}\text { млн. долл. } \\
\text { США }\end{array}$ & 150,0 & 183,9 & 154,7 & 176,9 & 197,2 & 150,8 \\
\hline
\end{tabular}

Примечание: Таблица подготовлена автором на основе отчётов о хозяйственной деятельности SOCAR. http://www.socar.az.

На основе Таблицы 1 можно заметить, что за последние годы общий объём переработки основных видов сырьевых ресурсов немного вырос, и это способствовало росту производства по основным видам продукции и полуфабрикатов. Динамика обеспечения основного вида сырья на предприятии ПО «Азерихимия» за 2010-2015 годы более наглядно видна на Рисунке 1 (всё это сырьё перерабатывается на установке «ЭП-300»).

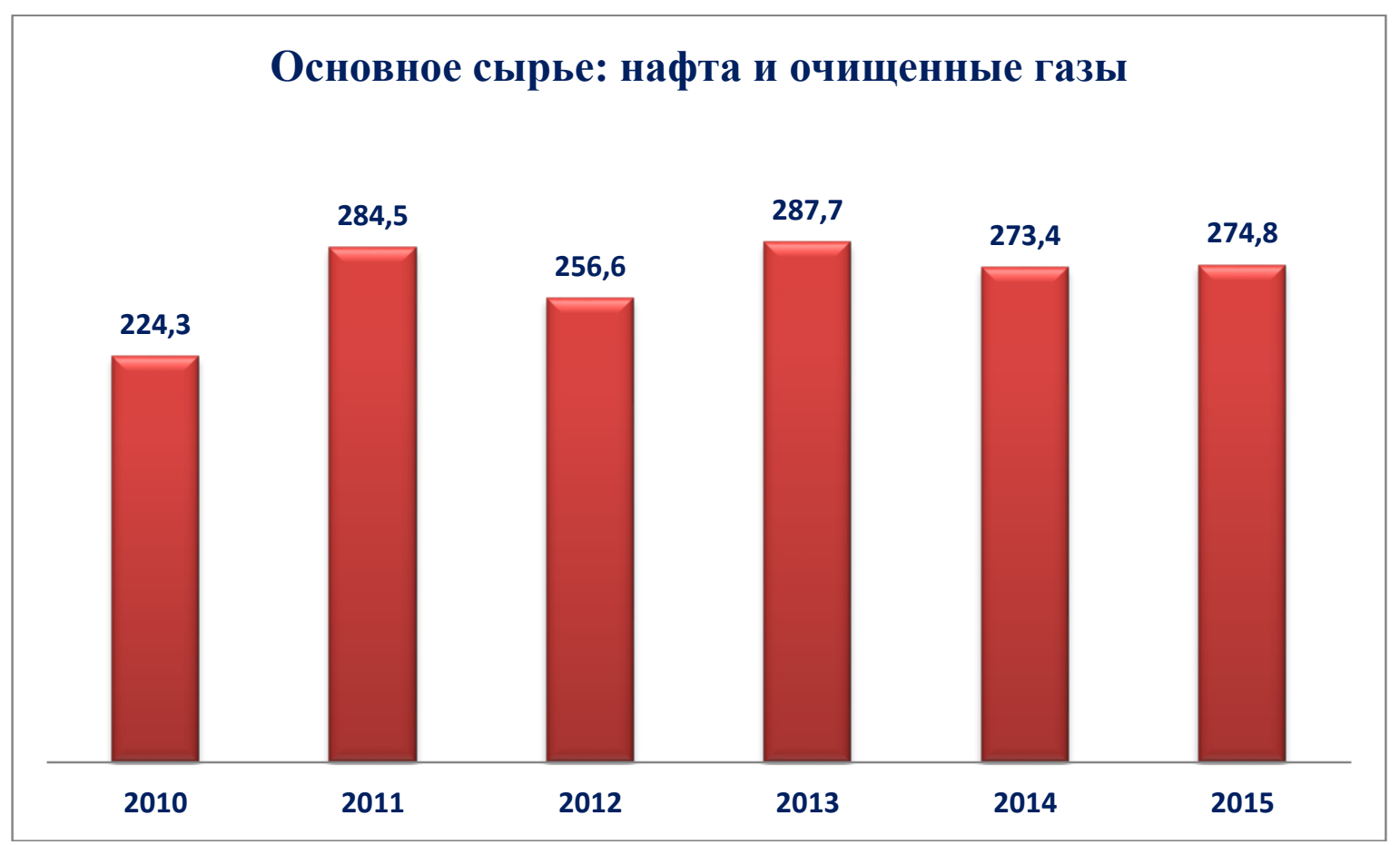

Рисунок 1 - Динамика обеспечения основного вида сырья на предприятии ПО «Азерихимия» за 2010-2015 годы, тыс. тон (разработано автором на основе отчётов SOCAR о хозяйственной деятельности. http://www.socar.az).

А на Рисунке 2 дана динамика производства основных видов полуфабрикатов и готовой продукции в Сумгайытском заводе «ЭтиленПолиэтилен» за 2010-2015 годы. 


\begin{tabular}{|c|c|c|c|c|c|c|}
\hline Impact Factor: & $\begin{array}{l}\text { ISRA (India) } \\
\text { ISI (Dubai, UAF } \\
\text { GIF (Australia) } \\
\text { JIF }\end{array}$ & $\begin{array}{r}=1.344 \\
=0.829 \\
=0.564 \\
=1.500\end{array}$ & $\begin{array}{l}\text { SIS (USA) } \\
\text { PИНЦ (Russia) } \\
\text { ESJI (KZ) } \\
\text { SJIF (Morocco) }\end{array}$ & $\begin{array}{l}=0.912 \\
=0.234 \\
=3.860 \\
=2.031\end{array}$ & $\begin{array}{l}\text { ICV (Poland) } \\
\text { PIF (India) } \\
\text { IBI (India) }\end{array}$ & $\begin{array}{l}=6.630 \\
=1.940 \\
=4.260\end{array}$ \\
\hline
\end{tabular}

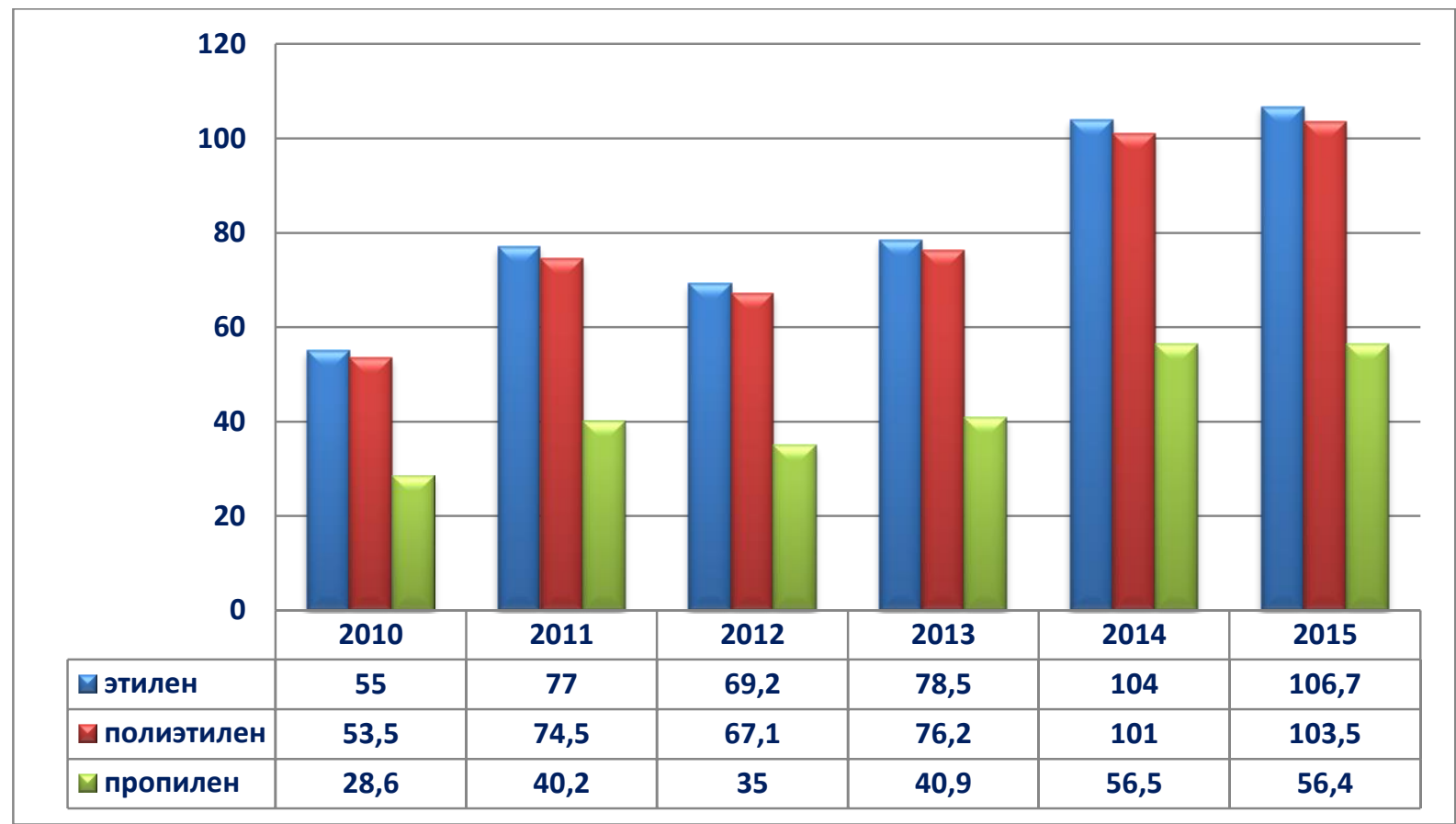

Рисунок 2 - Динамика производства основных видов полуфабрикатов и готовой продукции в Сумгайытском заводе «Этилен-Полиэтилен» за 2010-2015 годы, тыс. тон (разработано автором на основе отчётов SOCAR о хозяйственной деятельности. http://www.socar.az)

Кроме того, на Рисунке 3 наглядно рассмотрена динамика производства побочных, однако товарных продукций в Сумгайытском заводе «Этилен-Полиэтилен» за 2010-2015 годы.

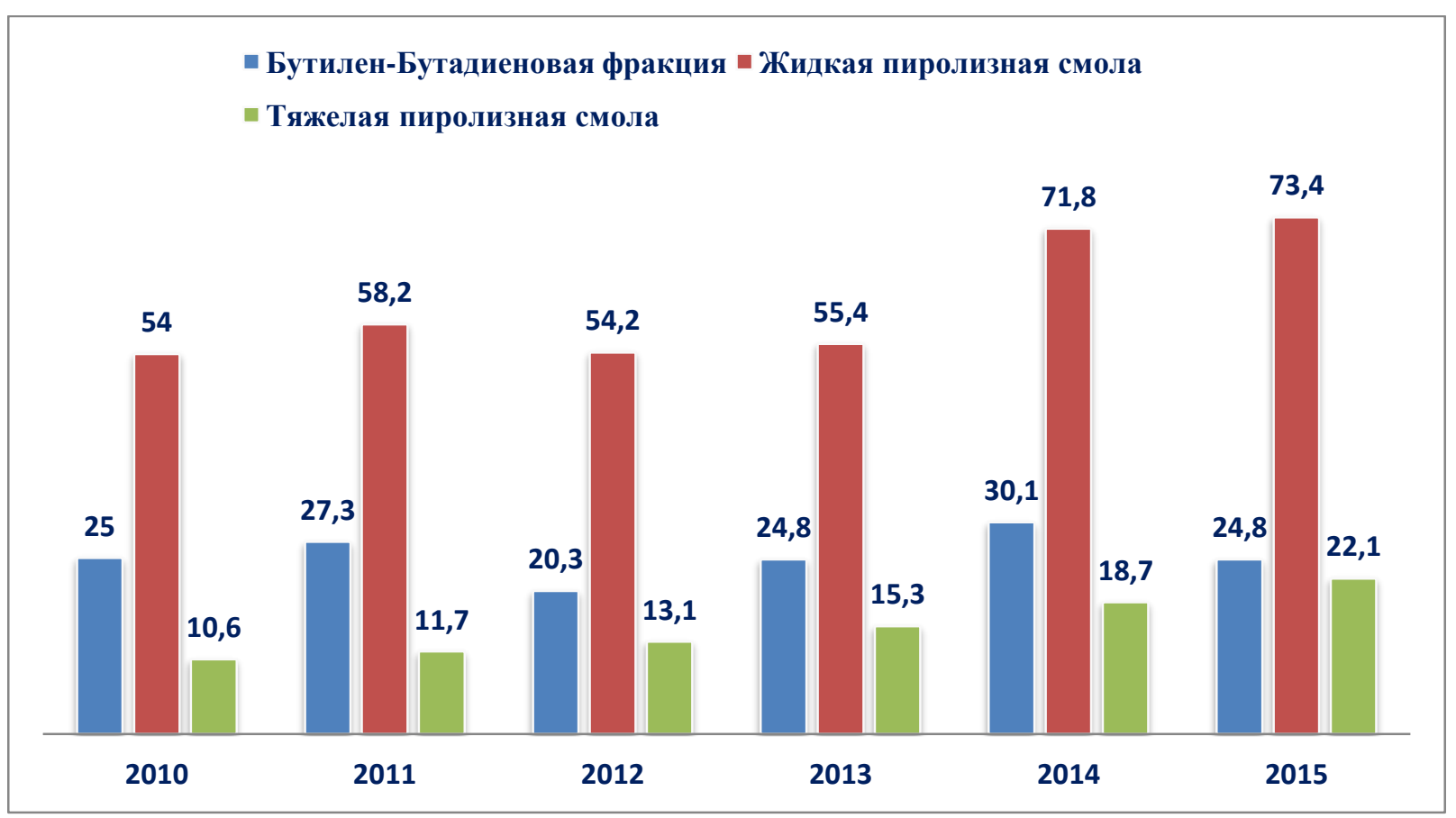

Рисунок 3 - Динамика производства побочных продукции в Сумгайытском заводе «ЭтиленПолиэтилен» за 2010-2015 годы, тыс. тон (разработано автором на основе отчётов SOCAR o хозяйственной деятельности. http://www.socar.az) 


\begin{tabular}{|c|c|c|c|c|c|c|}
\hline Impact Factor: & $\begin{array}{l}\text { ISRA (India) } \\
\text { ISI (Dubai, UAF } \\
\text { GIF (Australia) } \\
\text { JIF }\end{array}$ & $\begin{array}{l}=1.344 \\
=0.829 \\
=0.564 \\
=1.500\end{array}$ & $\begin{array}{l}\text { SIS (USA) } \\
\text { PИНЦ (Russia) } \\
\text { ESJI (KZ) } \\
\text { SJIF (Morocco) }\end{array}$ & $\begin{array}{l}=0.912 \\
=0.234 \\
=3.860 \\
=\mathbf{2 . 0 3 1}\end{array}$ & $\begin{array}{l}\text { ICV (Poland) } \\
\text { PIF (India) } \\
\text { IBI (India) }\end{array}$ & $\begin{array}{l}=6.630 \\
=1.940 \\
=4.260\end{array}$ \\
\hline
\end{tabular}

Отметим, что развитие химической промышленности и функционирование химических предприятий в Азербайджане не ограничиваются ПО «Азерихимия» компании SOCAR, есть ещё и другие предприятия, в основном частные малого и среднего субъекта предпринимательской деятельности. В целом, общий объём продукции и услуг в химической промышленности и по его цепям переработки в текущих ценах (млн. долл. США) и доля в общем объёме промышленной продукции в Азербайджанской Республике дана в Таблице 2.

Таблица 2

Объём продукции и услуги в химической промышленности и по его цепям переработке в текущих ценах (млн. долл. США) и доля в общем объёме промышленной продукции в Азербайджанской

Республике

\begin{tabular}{|c|c|c|c|c|c|c|c|c|c|c|c|c|c|c|}
\hline & \multicolumn{2}{|c|}{2010} & \multicolumn{2}{|c|}{2011} & \multicolumn{2}{|c|}{2012} & \multicolumn{2}{|c|}{2013} & \multicolumn{2}{|c|}{2014} & \multicolumn{2}{|c|}{2015} & \multicolumn{2}{|c|}{2016} \\
\hline & $\begin{array}{l}\text { млн. } \\
\text { долл } \\
\text { СШ } \\
\text { А }\end{array}$ & $\%$ & $\begin{array}{l}\text { млн. } \\
\text { долл } \\
\text { Сш } \\
\text { А }\end{array}$ & $\%$ & $\begin{array}{l}\text { млн. } \\
\text { долл } \\
\text { Сш } \\
\text { А }\end{array}$ & $\%$ & $\begin{array}{l}\text { млн. } \\
\text { долл } \\
\text { СШ } \\
\text { А }\end{array}$ & $\%$ & $\begin{array}{l}\text { млн. } \\
\text { долл } \\
\text { СШ } \\
\text { А }\end{array}$ & $\%$ & $\begin{array}{l}\text { млн. } \\
\text { долл } \\
\text { СШ } \\
\text { А }\end{array}$ & $\%$ & $\begin{array}{l}\text { млн. } \\
\text { долл } \\
\text { Сш } \\
\text { А }\end{array}$ & $\%$ \\
\hline $\begin{array}{l}\text { Химическая } \\
\text { промышленнос } \\
\text { ть }\end{array}$ & $\begin{array}{c}120 \\
3\end{array}$ & $\begin{array}{l}0, \\
4\end{array}$ & $\begin{array}{c}189, \\
0\end{array}$ & $\begin{array}{l}0, \\
5\end{array}$ & $\begin{array}{c}180 \\
6\end{array}$ & $\begin{array}{l}0, \\
5\end{array}$ & $\begin{array}{c}200 \\
3\end{array}$ & $\begin{array}{l}0, \\
6\end{array}$ & $\begin{array}{c}247 \\
2\end{array}$ & $\begin{array}{c}0,7 \\
7\end{array}$ & $\begin{array}{c}353, \\
2\end{array}$ & 1,4 & $\begin{array}{c}233 \\
6\end{array}$ & $\begin{array}{c}1,1 \\
5\end{array}$ \\
\hline $\begin{array}{l}\text { Производство } \\
\text { изделий резина } \\
\text { и пласмасса }\end{array}$ & 43,3 & $\begin{array}{l}0, \\
2\end{array}$ & 78,9 & $\begin{array}{l}0, \\
2\end{array}$ & 71,6 & $\begin{array}{l}0, \\
2\end{array}$ & 74,0 & $\begin{array}{l}0, \\
2\end{array}$ & 69 & $\begin{array}{c}0,2 \\
1\end{array}$ & 94,2 & $\begin{array}{c}0,3 \\
6\end{array}$ & $\begin{array}{c}112 \\
6\end{array}$ & $\begin{array}{c}0,5 \\
5\end{array}$ \\
\hline
\end{tabular}

Примечание: Таблица подготовлена автором на основе статистических данных Государственного Статистического Комитета Азербайджанской Республики. Азербайджан в циифрах, 2017. Баку, 2017.- 286 c. http://www.stat.gov.az.

Как видно из Таблицы 2, в 2016 году общий объем продукции и услуги в базовой химической промышленности Азербайджанской Республики в итоговом объёме промышленности страны немного снизился и это больше всего обуславливает применение продуктивных и прогрессивных инновационных функций и инновационной технологии, с целью увеличения возможности расширения производства перечня конкурентоспособных продукций, в том числе повышения экспортного потенциала страны.
Однако, к большому сожалению, темп и уровень применения инновационной технологии, инновационной функции и инновационной инвестиции в химических предприятиях страны находится на мизерном уровне[5]. На Рисунке 4 дана динамика и объём вложенных инвестиционных ресурсов в капиталовложения химических предприятий и их его доля в общих инвестиционных вложениях промышленного сектора Азербайджанской Республики за 2005-2015 годы. 


\begin{tabular}{|c|c|c|c|c|c|c|}
\hline Impact Factor: & $\begin{array}{l}\text { ISRA (India) } \\
\text { ISI (Dubai, UAF } \\
\text { GIF (Australia) } \\
\text { JIF }\end{array}$ & $\begin{array}{l}=1.344 \\
=0.829 \\
=0.564 \\
=1.500\end{array}$ & $\begin{array}{l}\text { SIS (USA) } \\
\text { PИНЦ (Russia) } \\
\text { ESJI (KZ) } \\
\text { SJIF (Morocco) }\end{array}$ & $\begin{array}{l}=0.912 \\
=0.234 \\
=3.860 \\
=\mathbf{2 . 0 3 1}\end{array}$ & $\begin{array}{l}\text { ICV (Poland) } \\
\text { PIF (India) } \\
\text { IBI (India) }\end{array}$ & $\begin{array}{l}=6.630 \\
=1.940 \\
=4.260\end{array}$ \\
\hline
\end{tabular}

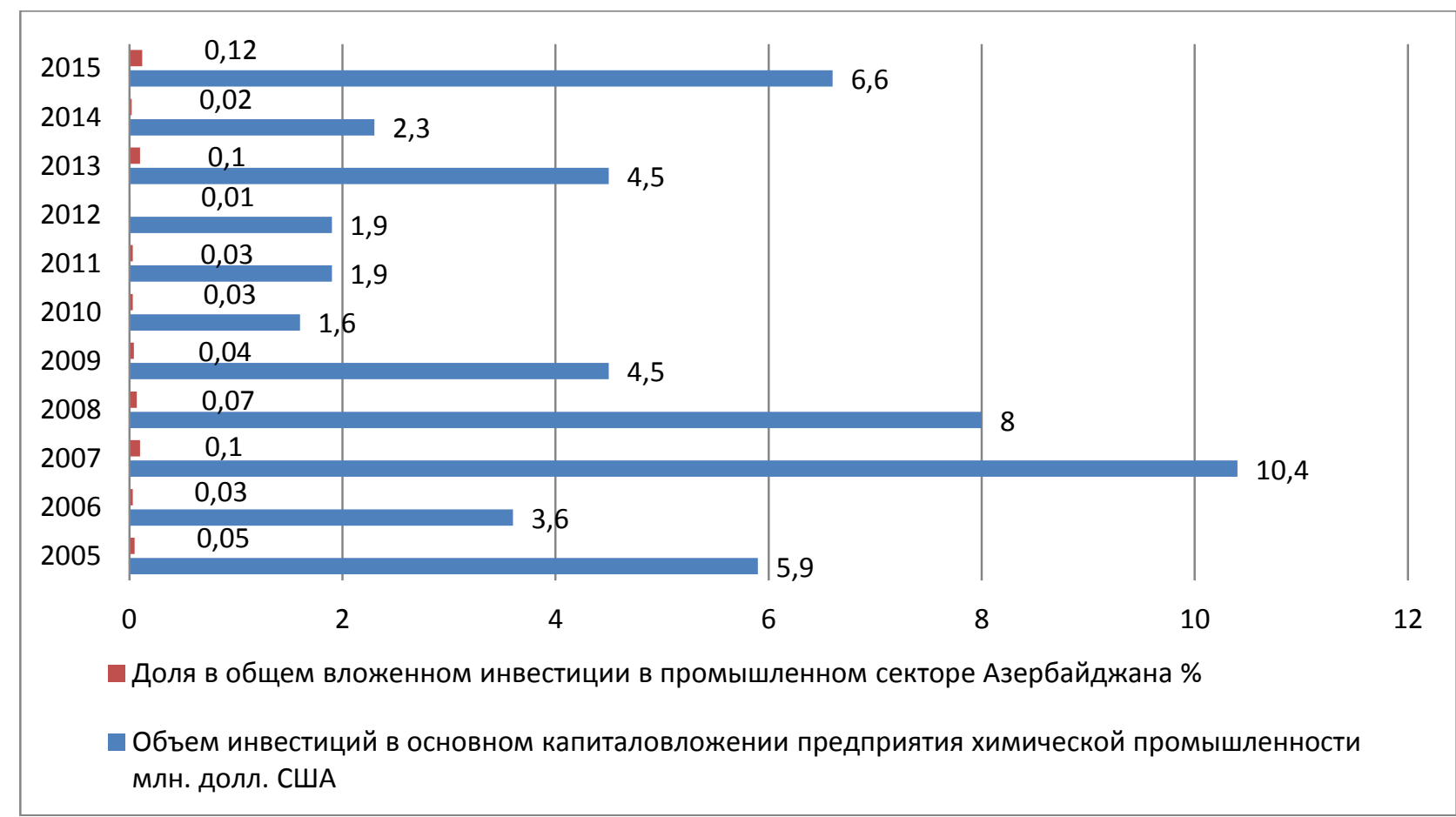

Рисунок 4 - Динамика и объём вложенных инновестиционных ресурсов в капиталовложения химических предприятий и их его доля в общих инвестиционних вложениях промышленного сектора Азербайджанской Республики за 2005-2015 годы. Подготовлено автором на основе статистических данных Государственного Статистического Комитета Азербайджанской Республики. Азербайджан в цифрах, 2017. Баку, 2017.- 286 c. http://www.stat.gov.az.

Как видно из Рисунка 4 объём инвестиций в основном капиталовложения предприятий химической промышленности Азербайджана незначительны, и это обстоятельство не позволяло увеличить уровень обновления основных фондов и тем самым способствовать интенсификации, инноватизации предприятий химической промышленности страны (см. Рисунок 5)

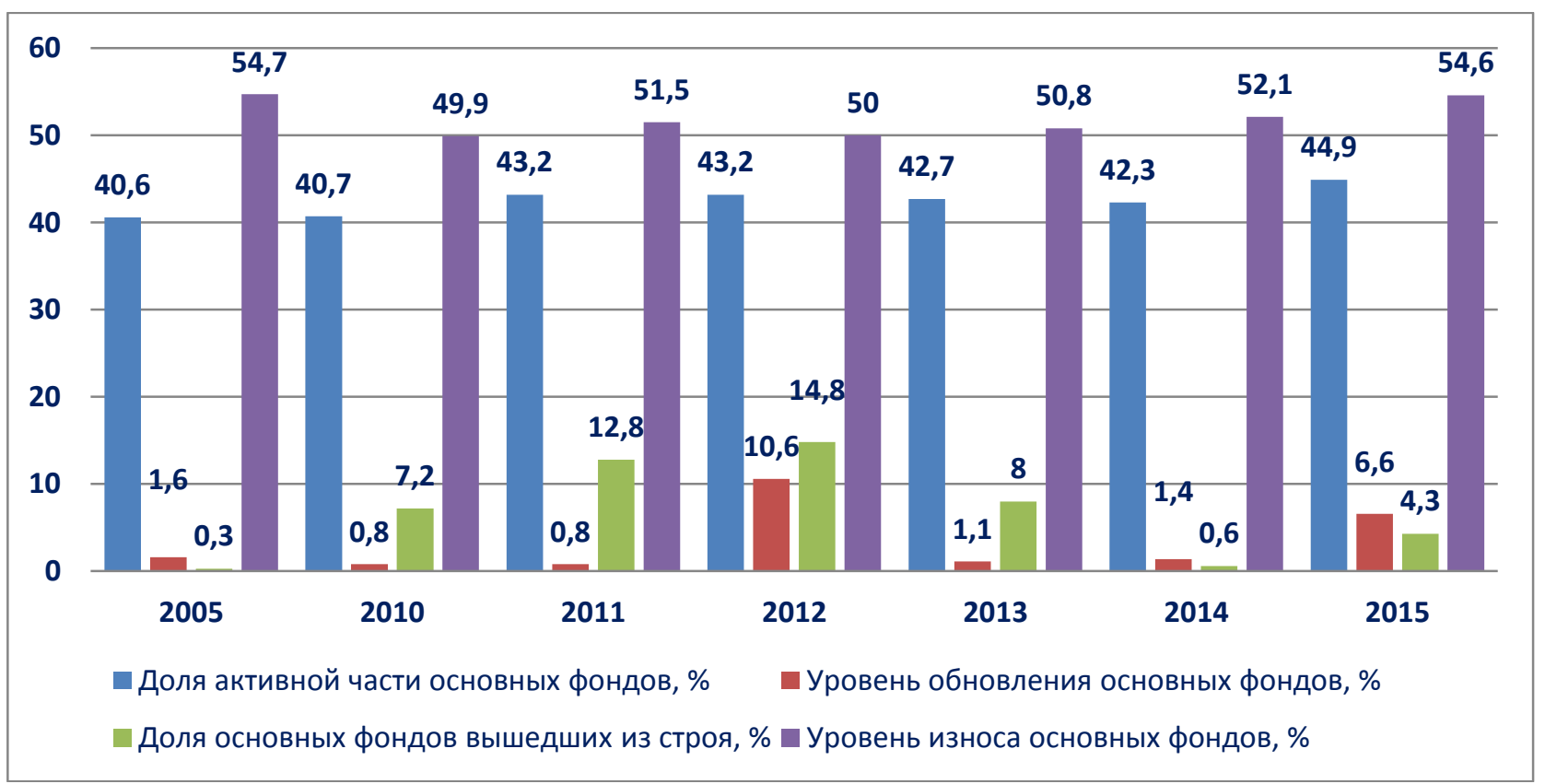

Рисунок 5 - Уровень обновления и износа основных фондов предприятий химической промышленности Азербайджана. Подготовлено автором на основе статистических данных

Государственного Статистического Комитета Азербайджанской Республики. http://www.stat.gov.az. 
Рисунок 5 свидетельствует о важности обновления основных фондов и обязательной инноватизации предприятий химической промышленности в ближающей перспективе. Профессор Т.Алиев справедливо считает, что Азербайджану следует не затягивать применение инноватизационных функций в предприятиях химии и нефтехимии в стране[6]. Из-за слабой инноватизации предприятия химической промышленности и общий объём инноватизационной продукции, расход на инноватизационную продукцию находится на низком уровне (см. Рисунок 6).

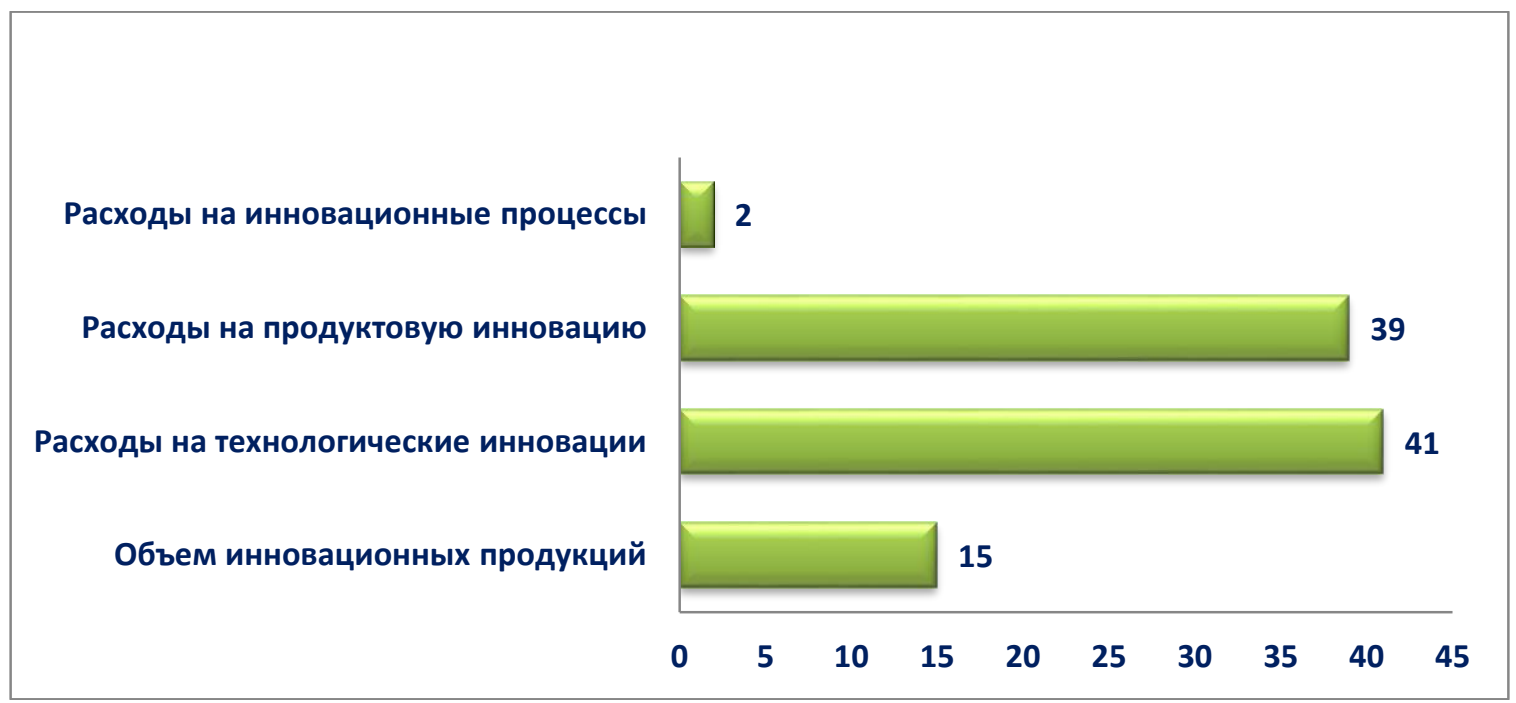

Рисунок 6 - Объем инновацизационной продукции и расходы на технологической инновацизации в предприятий химической промышленности Азербайджана. Подготовлено автором на основе статистических данных Государственной Статистического Комитета Азербайджанской Республики. http://www.stat.gov.az.

На основе Рисунка 6 можно сделать вывод, что в Азербайджане требуется коренное изменение инновационной экономической политики, и обеспечить более продуктивные механизмы инновационной деятельности. Кроме того, требуется активизировать инновационные деятельности малых и средних предприятий в стране[7]. Тем более, уже действует с представлением налоговой льготы на 7 лет Сумгайытский Промышленно-Химический Парк, созданный согласно Указу Президента Азербайджанской Республики от 21 декабря 2011 года[8]. В составе парка зарегистрировано уже 9 резидентов и вложено свыше 1,1 млрд. долларов США в инвестиционные ресурсы на строительство инновационно-химической предприятие. Кроме того, в следующем году будет издана в эксплуатацию крупный инновационное предприятие - Завод Карбамид в Сумгайытском Химическом Центре[9]. Намечается существенного изменение структуры конкурентоспособных продукций химической промышленности страны, путем применение инновационных технологий[10]. Отметим, что одной из крупных частных инновационной химической предприятий - Завод Метанол компании Азмеко из-за не стабильного обеспечения основным видом сырья - природным газам, не смог успешно функционировать и был куплен компаниям SOCAR[11].

\section{Conclusion}

Таким образом, можно сделать вывод о том, что в ближающей перспективе имеется реальные шансы и потенциал по интенсификации и расширении применение инновационной функции и технологи в предприятиях химической промышленности Азербайджана и обеспечит рост и объем, также расширит перечень инновационной продукции и т.д. 


\begin{tabular}{l|lrl|l|ll} 
& ISRA (India) & $=\mathbf{1 . 3 4 4}$ & SIS (USA) & $=\mathbf{0 . 9 1 2}$ & ICV (Poland) & $=\mathbf{6 . 6 3 0}$ \\
Impact Factor: & ISI (Dubai, UAE) $=\mathbf{0 . 8 2 9}$ & PUHL (Russia) $=\mathbf{0 . 2 3 4}$ & PIF (India) & $=\mathbf{1 . 9 4 0}$ \\
& GIF (Australia) & $\mathbf{0 . 5 6 4}$ & ESJI (KZ) & $=3.860$ & IBI (India) & $=\mathbf{4 . 2 6 0}$
\end{tabular}

\section{References:}

1. Aliyev SH.T. (2012) Otsenki i napravleniya modernizatsii khimicheskogo neftekhimicheskogo kompleksa Azerbaydzhana. Baku, «Nauka i obrazovaniye», $-156 \mathrm{p}$.

2. Aliyev SH.T. (2010) Voprosy razvitiya khimicheskoy promyshlennosti Azerbaydzhanskoy Respubliki // Zhurnal «Khimicheskaya promyshlennost' Rossii segodnya». Moskva, №8, -p. 5-9.

3. (2010) Rasporyazheniye Prezidenta Azerbaydzhanskoy Respubliki ot 2-go aprelya 2010 goda «O sovershenstvavonii mekhanizmov upravleniya $\mathrm{v}$ neftekhimicheskoy promyshlennosti».

Available: http://www.socar.az.

4. (2015) Otchety o khozyaystvennoy deyatel'nosti SOCAR za 2010-2015 gody. Available: http://www.socar.az. (Accessed: 10.07.2017).

5. Aliyev T.N., Mamedova S.R. (2017) Organizatsionno-ekonomicheskiye mekhaniko-tekhnologicheskiye faktory, vliyayushchiye na innovatsionnoye razvitiye khimicheskikh predpriyatiy Azerbaydzhana // Zhurnal «Nauchnyye Proizvedeniya». Institut
Ekonomiki Natsional'naya Akademiya Nauk Azerbaydzhana. №2, - p. 35-44.

6. Aliyev T.N. (2016) Innovatizatsionnaya razvitiya promyshlennosti Azerbaydzhana: neftepererabotka, khimiya i neftekhimiya. Moskva-Berlin, "Palmarium", - 232 p.

7. Aliyev T.N. (2014) Organizatsionnoekonomicheskiye aspekty innovatsionnoy deyatel'nosti malykh i srednikh predpriyatiy $\mathrm{v}$ Azerbaydzhane // Zhurnal «Informatsiya i innovatsiya». Moscow, №3-4, p. 106-116.

8. (2011) Ukaz Prezidenta Azerbaydzhanskoy Respubliki «O sozdanii Sumgayytskogo Promyshlennogo Khimicheskogo Parka». g. Baku, 21 dekabrya 2011 goda, №548.

9. (2017) Zavod Karbamid. SOCAR, Available: http://www.socar.az. (Accessed: 10.07.2017).

10. (2015) Spravka po khimicheskoy promyshlennosti. Ministerstvo ekonomiki i promyshlennosti Azerbaydzhanskoy Respubliki. Baku, 2015. Available: http://www.economy.gov.az. $\quad$ (Accessed: 10.07.2017).

11. (2017) "SOCAR" proizvel predvaritel'nuyu oplatu za Zavod Metanol $247 \mathrm{mln}$. doll. SSHA. Available: http://www.anews.az. (Accessed: 10.07.2017). 